\title{
Las funciones comando de Madrid en la economía global: una aproximación a través del proceso de atracción de capital extranjero
}

\begin{abstract}
The dynamism of the metropolis of Madrid and its intense spatial restructuring has been explained by the processes of globalization and technological change. This has generated a discussion about its condition as a global city. This article initially presents the limits of the concept as apparent in the international debate, then immerses itself in the issue from the perspective of the attraction of foreign capital. The analysis of diverse statistical sources confirms the high sectoral concentration of so-called command functions (financial services and advanced firm services). This concentration in the city centre, in spite of competition from new location types in the surrounding metropolitan area (business parks, financial cities), are aspects that have to be incorporated into any reflection on the balanced and sustainable growth of Madrid and other metropoli in the current phase of capitalist development.
\end{abstract}

Key words: foreign capital, command functions, Madrid, global city.

Resumen

El dinamismo de la metrópoli de Madrid y su intensa reestructuración territorial vienen siendo explicados desde la globalización y el cambio tecnológico, abriendo con ello el debate sobre su condición de ciudad global. Una vez precisados los límites del concepto de acuerdo con el debate internacional, este trabajo se asoma a la cuestión desde la perspectiva de la atracción de capital extranjero. El análisis de algunas fuentes estadísticas inéditas confirma la elevada concentración sectorial en las llamadas funciones comando (servicios financieros y servicios avanzados a las empresas). Su acusada concentración en la ciudad central, a pesar de la competencia de nuevas formas de acomodación en la zona metropolitana colindante (parques empresariales, ciudades financieras...), son aspectos a incorporar a la reflexión sobre el crecimiento equilibrado y sostenible de Madrid y de otras metrópolis en la actual fase de desarrollo capitalista.

Palabras clave: capital extranjero, funciones comando, Madrid ciudad global. 


\section{Introducción}

$\mathrm{E}$ n las últimas décadas no ha dejado de crecer el interés por las transformaciones recientes de las grandes metrópolis del mundo, asociadas a la globalización y al cambio tecnológico en la nueva fase de desarrollo capitalista. Dichas transformaciones vienen siendo objeto de seguimiento e interpretación en las principales regiones metropolitanas del mundo desarrollado (ver, por ejemplo, Castells, 1989; Knox \& Taylor, 1995; Sassen, 1998, 2003) y en países en desarrollo, comenzando por las grandes metrópolis latinoamericanas (De Mattos, 2002; Rojas, Cuadrado-Roura \& Fernández Güell, 2005).

Aunque la ligazón entre globalización y procesos de urbanización no es nueva, es a partir de la década de los setenta cuando se hace evidente la aceleración de los procesos de globalización del capital, el trabajo y la cultura, y los efectos significativos que esta intensa globalización tiene sobre las ciudades y la vida urbana en todo el mundo (Soja, 2005, p. 46). La variedad de dichos efectos, que hacen referencia tanto a la evolución reciente de la estructura y morfología interna de las metrópolis, como a sus límites externos y sus relaciones con el entorno, habría favorecido la proliferación de neologismos y metáforas que tratan de describir las nuevas formas urbanas resultantes (Ramírez, 2006; Méndez, 2007). De entre toda ellas, cabe destacar un primer grupo de propuestas que apunta al cambio en la organización, el contenido funcional y el protagonismo de las ciudades en la era del capitalismo global, en relación con una nueva base económica metropolitana altamente terciarizada y una nueva arquitectura productiva como respuesta a esa economía de archipiélago propuesta por Veltz (1996), que fomenta la conexión de ciudades con similares roles en la economía mundial a través de redes transfronterizas (De Mattos, 2002).

Es a partir de procesos de esta índole desde los que se ha tratado de dar explicación al dinamismo económico de la metrópoli de Madrid y a su

* Instituto de Economía, Geografía y Demografía, Consejo Superior de Investigaciones Científicas, Madrid, España. E-mail: ssanchez@ieg.csic.es, chon@ieg.csic.es, aname@ieg.csic.es.

Recibido el 30 de agosto de 2007

Aceptado el 4 de diciembre de 2008 intensa transformación territorial en las últimas décadas (Méndez et al., 2006), aludiendo de forma explicita en algunos casos al concepto de ciudad global (Estébanez, Molina \& Pérez Sierra, 1993; Martín-Roda, 1997). Dejando a un lado cierta ambigüedad en el uso de conceptos y criterios metodológicos, muchos de los cuales estaban siendo ajustados en la literatura internacional, lo cierto es que de los trabajos empíricos se concluye que efectivamente Madrid se integra en la cadena mundial de metrópolis, aunque su importancia relativa le confiere aún el calificativo de ciudad de segundo orden o "ciudad global emergente" (Molina, 2002).

Por lo tanto, una vez precisados los límites del concepto de ciudad global, el objetivo de este trabajo es estudiar el proceso de atracción de capital extranjero en Madrid hacia las llamadas funciones centrales o de comando en la economía global (servicios financieros y servicios avanzados a las empresas). Esto nos sitúa en la órbita de los trabajos de la red de investigación del Globalization and World Cities Study Group and Network (en adelante GaWC), que, a partir de las tesis sobre el crecimiento de las actividades de servicios en la economía actual y el papel de los servicios a la producción avanzados, cuya presencia destacaría especialmente en las ciudades mundiales (Sassen, 1998), propone una nueva manera de aproximación a la cuestión en la que las empresas de servicios son los sujetos de la investigación, mientras las ciudades los objetos últimos de estudio (Taylor, Walter \& Beaverstock, 2002, p. 4).

Conviene aclarar en este punto que el desarrollo de la metodología del GaWC exigiría un estudio pormenorizado de la presencia y participación de Madrid en las redes globales de oficinas de firmas internacionales de servicios avanzados (Taylor, 2001). Dada la falta de estudios monográficos previos, con este trabajo pretendemos cubrir una etapa inicial en la investigación, aproximándonos a la cuestión de las funciones comando en Madrid desde la óptica concreta del grupo de empresas extranjeras (más del $50 \%$ de participación extranjera en su capital) en servicios financieros y a las empresas, el que a priori parece llamado a detentar el máximo protagonismo en las mencionadas redes globales de oficinas que 
conectarían las principales capitales del mundo. Por este motivo, de forma secundaria, se plantea aquí su caracterización en términos comparativos con el de las empresas nacionales ${ }^{1}$.

Para alcanzar estos objetivos contamos, además de la información sobre los flujos de inversión extranjera directa (IED), con dos fuentes estadísticas inéditas. En primer lugar, los llamados Grupos de empresas del Directorio Central de Empresas (DIR$\mathrm{CE})$, cuya explotación para la región de Madrid fue realizada ex profeso por el Instituto Nacional de Estadística (INE) para esta investigación. En segundo lugar, una explotación de la base de datos Sistema de Análisis de Balances Ibéricos (en adelante SABI), que nos permite adentrarnos en las características económico-financieras de las empresas extranjeras. La complementariedad de ambas fuentes se ve reforzada ante el mayor detalle sectorial y espacial que permite la segunda de ellas.

En resumen, comenzamos presentando los principales elementos de la discusión teórica, tanto desde la perspectiva del fenómeno de crecimiento e internacionalización de los servicios avanzados, como de la propia noción de ciudad global. A partir de aquí, se presentan los resultados del análisis estadístico de la información sobre los flujos de IED, los grupos internacionales de empresas y las empresas extranjeras, planteando un recorrido desde la escala regional a la urbana. La última parte del trabajo se dedica a la geografía de las funciones comando en la metrópoli madrileña.

\section{Del crecimiento e internacionalización de los servicios avanzados al concepto de ciudad global.}

\section{Sobre la importancia de los servicios avanzados en la economía actual.}

Como es bien sabido, la terciarización de la base económica metropolitana supondría una de

\footnotetext{
Ante la común falta de desagregación territorial de los estudios comparativos entre empresas extranjeras y nacionales (Mancebón Torrubia \& Chavarría Lozano, 2001), cobran interés las comparaciones planteadas a partir del SABI para la región y la ciudad de Madrid, en el marco del proyecto del Observatorio Industrial de Madrid, suscrito entre el Ayuntamiento de Madrid y el instituto de Economía y Geografía del CSIC.
}

las características más destacadas de la evolución reciente de muchas metrópolis, en lo que diversos autores consideran el proceso de conformación de una economía servindustrial, donde la creciente integración entre actividades industriales y de servicios no implica el fin de la industria como motor de crecimiento (Daniels \& Bryson, 2002).

Uno de los rasgos más característicos de esta nueva economía servindustrial sería, sin duda, el crecimiento de los llamados servicios a las empresas (o a la producción); un heterogéneo conjunto de actividades con evidentes contrastes en cuanto a sus características internas, dinamismo y capacidad de arrastre del conjunto de la economía. Destaca, en este sentido, el estratégico grupo de los servicios a las empresas "avanzados" (contabilidad y auditoria, servicios legales, estudios de arquitectura e ingeniería, actividades informáticas, investigación y desarrollo, etc.), con frecuencia intensivos en información y conocimiento (lo que algunos llaman el sector "cuaternario"); frente a los considerados habitualmente como servicios "banales" (seguridad, limpieza, mantenimiento, colocación de personal, etc.). Teniendo en cuenta esta diversidad, el crecimiento de los servicios a las empresas respondería a un conjunto diverso de causas explicativas (Cuadrado-Roura \& Rubalcaba Bermejo, 2000; Muñoz Guarasa, 2005; Martínez, Rubiera, 2006): i) Aumento de la complejidad en la organización de las empresas y sus nuevas necesidades ante la ampliación de los mercados y la internacionalización de las actividades; ii) Procesos de terciarización industrial como consecuencia del aumento en la cadena de valor empresarial de las tareas previas y posteriores a la fabricación, que con frecuencia son externalizadas a empresas especializadas (outsourcing); iii) El avance de las tecnologías de la información y comunicaciones representa una fuente de oportunidad para las empresas, que precisa del concurso de servicios avanzados; iv) A todo lo anterior habría que sumar los factores derivados de la intervención de los Estados, regulaciones sobre el uso de servicios, certificaciones, etc.

Un aspecto esencial del proceso de expansión de los servicios a las empresas es el de su internacionalización, impulsada en los últimos años ante la progresiva saturación de los mercados interiores 
y el desarrollo de las tecnologías de la información y comunicaciones, algo de enorme importancia dada la naturaleza intangible y perecedera de estos servicios, lo que en muchos casos exige ser producidos y consumidos simultáneamente (Boddewyn, Halbrich \& Perry, 1985).

En ese sentido, ha sido destacada la importancia de la IED como principal modo de entrada, con un dominio claro de fusiones y adquisiciones transfronterizas dentro de los flujos globales (Sassen, 2003; Rodríguez-Pose \& Zademach, 2003), si bien, como en el caso de la industria, van ganando protagonismo otros tipos de entradas (licencias, franquicias, joint-ventures, acuerdos de cooperación, alianzas internacionales). Los estudios internacionales han tratado de explicar esta primacía desde el llamado paradigma ecléctico (Dunning, $1979,1985)$, que alude a las preferencias de internacionalización de empresas multinacionales, sobre todo del sector manufacturero y de la industria extractiva, a partir de la combinación de tres tipos de ventajas especificas: de activos y de propiedad, de localización y de internacionalización. De los intentos de traslación al ámbito de los servicios a las empresas, en general mucho menos estudiado, se obtienen conclusiones de evidente interés para este trabajo (Boddewyn, Halbrich \& Perry, 1985; Bagchi-Sen \& Sen, 1997):

Las ventajas específicas de activos y de propiedad, con frecuencia de carácter intangible y relacionadas con el tamaño, la experiencia en mercados internacionales, posesión de una tecnología, información, imagen de calidad de la marca, etc., permitirían a las multinacionales competir satisfactoriamente con empresas locales en entornos extranjeros desconocidos, superando así las desventajas naturales que suponen las diferencias culturales, lingüísticas, institucionales, etc. Las mayores empresas transnacionales de contabilidad y auditoria, conocidas como "Big Four", así como

Si en las décadas de los setenta y ochenta se hablaba de los "Big Eight", su número ha ido progresivamente reduciéndose fruto de la concentración del sector a través de fusiones, permaneciendo en 2004 cuatro grandes corporaciones internacionales: PricewaterhouseCoopers (PWC), Ernst \& Young (EY), KPMG (Klynveld Peat, Marwick Goerdeler) y Deloitte (Deloitte Touche Tohmatsu o DTT). las grandes compañías de publicidad, ofrecerían buenos ejemplos de dominación global.

Por su parte, determinadas ventajas específicas de internacionalización explicarían que, de cara a la transferencia de información y conocimiento, las empresas prefieran crear mercados internos bajo su control a través de la IED, antes que operar a través de mercados externos (exportación, licencias, etc.). Por ejemplo, en servicios como publicidad o marketing la confidencialidad se aseguraría mejor en mercados internos; mientras que en contabilidad o servicios legales, la necesidad de superar las regulaciones nacionales a la actividad (licencias, colegios profesionales), unida a la importancia de los contactos cara-a-cara con los clientes, impulsaría también la internacionalización a través de la IED (en este caso más que la propiedad mayoritaria se buscarían redes de coaliciones con socios locales). Por otro lado, en servicios no basados en el conocimiento, como por ejemplo la banca, la presencia local es necesaria para asegurar la prestación de un servicio de calidad.

Las ventajas específicas de localización harían referencia a un conjunto de variables relacionadas con la propia "transportabilidad" del servicio y el aprovechamiento de economías de aglomeración, tanto en el país de origen como en el de acogida. A modo de ejemplo, las necesidades de contacto con una clientela diversificada, de un ambiente propicio para los negocios, de mano de obra local cualificada o del acceso al capital internacional y a las redes de comunicaciones, serían algunas de las variables con mayor peso en las decisiones de la banca comercial, compañías de seguros, de contabilidad, publicidad, etc.

Con todo, la explicación del fenómeno de expansión de los servicios avanzados a la producción nos lleva necesariamente a plantear la discusión sobre el concepto de ciudad global, al evidenciarse que "el desarrollo de mercados globales para servicios financieros y al productor, así como el crecimiento de la inversión como un importante tipo de transacción internacional, han contribuido a la expansión de las funciones de alta gestión y a la demanda de servicios especializados para las empresas (...) las funciones centrales para la gestión y coordinación de sistemas económicos globales están desproporcionadamente 
concentradas en los países altamente desarrollados -particularmente, aunque no exclusivamente-, en ciudades globales" (Sassen, 2003, p. 9).

\section{Revisión del concepto de ciudad global.}

Detrás del concepto de ciudad global existe una extensa literatura internacional. Recordando la publicación en los últimos años de algunos valiosos ejercicios de sistematización (Sassen, 1998; Beaverstock, Smith, Taylor, 2000; Soja, 2005), nos limitamos a señalar a continuación dos hitos fundamentales del debate. Nos referimos, en primer lugar, a la publicación de los trabajos de Friedmann, donde se formula por primera vez la ya célebre hipótesis de las ciudades mundiales ("the world cities hipothesis"). Según ésta, en el contexto de la reestructuración industrial y la reorganización especial desencadenada en la nueva división internacional del trabajo durante la década de los setenta, determinadas ciudades a través del mundo serían usadas por el capital global como puntos base en la organización espacial y la articulación de la producción y los mercados. De la existencia de estos vínculos se derivaría la existencia de una jerarquía compleja de ciudades mundiales (Friedmann \& Wolff, 1982; Friedmann, 1986). Por otro lado, los atributos que se suponen a este grupo de ciudades plantean una concepción algo amplia del problema, incluyéndose entre otros aspectos la presencia de centros financieros, sedes de multinacionales, servicios a las empresas, centros manufactureros importantes, nodos de transporte o incluso el propio tamaño de las ciudades.

Directamente relacionado con las tesis sobre la emergencia de la sociedad en red (Castells, 1996), cabe destacar, en segundo lugar, el concepto de ciudad global acuñado por Saskia Sassen (Sassen, 1991, 1998, 2003), posiblemente la propuesta de mayor calado de los últimos años. Así las cosas, las ciudades globales son consideradas, tal como adelantamos, lugares privilegiados para la producción de las llamadas funciones centrales o de comando, necesarias para la implementación y gestión de los sistemas económicos globales, incluyendo no solo el tipo de funciones que se desarrollan en el seno de las sedes de empresas, sino también funciones financieras, legales, contables, de gestión, ejecutivas, etc., frecuentemente subcontratadas al sector de servicios altamente especializados.
Aunque parcialmente integrado en la estructura de gestión general de la economía nacional, este subsector puede ser concebido como "parte de una red que conecta las ciudades globales a través del mundo por medio de filiales de empresas u otras oficinas representativas, servicios especializados y gestión de las transacciones en el mercado global de capitales y de inversión extranjera" (Sassen, 2003, p. 10).

Este concepto de ciudad global plantearía algunas diferencias importantes respecto de otras propuestas teóricas, comenzando con la consideración conjunta dentro de las funciones centrales, de la banca-finanzas y servicios a las empresas avanzados. Además, según se ha apuntado recientemente, la propuesta habría sido valorada críticamente por autores de la teoría urbana y regional en el entorno de la Universidad de Los Ángeles, para los que las ciudades-región globales serían, tras el proceso de reestructuración industrial de las ultimas décadas, una clara expresión del capitalismo urbano industrial, por oposición a los que "tendieron a adoptar la versión más cómoda de la tesis de sociedad postindustrial, que percibe la ciudad global como una ciudad desmantelada industrialmente y dominada por el poderoso sector terciario de finanzas, seguros y bienes inmuebles" (Soja, 2005, p. 49).

Terminamos este repaso teórico recordando que aunque la noción de ciudad global se centra en los procesos económicos (globalización, terciarización, fragmentación productiva...) más que en el tamaño o la forma urbana resultante, no debemos perder de vista el impacto que dichos procesos tienen en la reestructuración territorial de las metrópolis. Para su estudio conviene recordar, primero que todo, los principales factores de localización identificados en el caso de los servicios avanzados, cuya incidencia varía según escalas geográficas. A escala interurbana se alude a factores como la calidad de las infraestructuras de transporte y comunicaciones en relación con una elevada accesibilidad, además de la concentración de fuentes de información y conocimiento (empresas, medios de comunicación, universidades, instituciones públicas...), facilidad para establecer relaciones profesionales cara-a-cara, o disponibilidad de personal cualificado. Mientras que escala 
intraurbana destaca, sobre todo, la localización en lugares de prestigio o simbólicos, lo cual permite a las empresas proyectar una imagen de calidad y solvencia del negocio, o determinadas características de la oferta de locales y oficinas (Pascual Esteve, 1990; Illeris, 1997, Wood, 2002).

Estos factores tendrían su reflejo en la acusada concentración de estas actividades en el corazón de las ciudades, con procesos locales de descentralización de desigual importancia. Ambos aspectos deben ser relacionados con el proceso de reestructuración socioterritorial que en las últimas décadas ha supuesto la recuperación del protagonismo de los grandes centros urbanos en el capitalismo global, pero también nuevas y complejas modalidades de expansión metropolitana (suburbanización, policentrismo, fragmentación, polarización social...); todo ello sin perder de vista la diversidad de trayectorias metropolitanas existente, fruto de la desigual herencia cultural, económica y territorial, y de la diversidad de respuestas ofrecidas por los actores locales (Ciccolella, 1999; De Mattos, 1998, 2002; Méndez, 2001).

Con todo, cabe señalar algunas tendencias comunes en cuanto a la evolución en las formas de acomodación urbana de las funciones de comando. Destaca, en primer lugar, la tradicional concentración de ese terciario avanzado en los centros urbanos tradicionales, en especial en los distritos centrales de negocios, así como la aparición de subcentros de actividad, sobre todo comercial y de servicios a las empresas, como respuesta a los intensos procesos de metropolización ocurridos desde la década de los ochenta en la mayoría de las grandes ciudades de los países avanzados. A partir de ahí, durante la década siguiente surgirían nuevas centralidades en la región metropolitana, beneficiadas por la mejora de las infraestructuras y la accesibilidad alcanzada gracias a las nuevas tecnologías de la información y las comunicaciones, lo que posibilita la localización de parte de ese tejido productivo en nuevos espacios de actividad fuera de la ciudad central. En los últimos años, los contenedores urbanos ya habituales en esas periferias, como parques empresariales y de oficinas, parques tecnológicos, etc., van cediendo protagonismo a nuevas y sofisticadas formas de acomodación del terciario direccional en ciudades corporativas, ciudades financieras, etc.

A pesar de los procesos de renovación urbana que han afectado desde el comienzo de la reestructuración territorial a los centros tradicionales de las metrópolis, los distritos de negocios en ellos enclavados han continuado aglutinando el grueso del terciario direccional, beneficiándose de importantes economías de aglomeración, que se refuerzan a partir de la elevada centralidad y prestigio del emplazamiento. En el momento actual se reavivan los debates sobre los problemas que ello produce desde la perspectiva de la segregación de otras actividades económicas, la polarización social o el equilibrio territorial, aspectos todos ellos presentes en las acepciones modernas de la competitividad urbana.

\section{La internacionalización de la economía madrileña: los flujos de inversión extranje- ra directa.}

Aunque el resto de las fuentes estadísticas empleadas en este trabajo permiten un mayor detalle sectorial y espacial, el análisis de los flujos de IED aporta las primeras evidencias sobre el acusado grado de internacionalización de la economía madrileña, lo cual, como vimos, se relaciona con el aumento de la demanda, complejidad y escala de los servicios avanzados para la implementación y gestión de los sistemas económicos globales (Sassen, 1991).

El proceso de atracción de IED ha sido determinante en el desarrollo económico de España, sobre todo a partir de la década de los setenta, reforzándose a raíz de la integración en la Comunidad Europea y potenciándose durante la década de los noventa al considerarse como país con gran atractivo inversor, ocupando durante ese período el sexto lugar como destino de IED. De acuerdo con las tendencias de los últimos años, la Comunidad de Madrid se perfila como el principal foco receptor y emisor de inversiones a escala nacional.

Según los últimos datos disponibles, del total de IED llegada al país entre 2000 y 2006, esto es, 95.000 millones de euros ${ }^{3}$, más del 52\% se destinó

\footnotetext{
3 No incluye las operaciones de empresas de tenencia
} 
a empresas con sede social en la Comunidad de Madrid. Como en otras regiones de países desarrollados, las modalidades de inversión más frecuentes correspondieron, sobre todo, a reestructuraciones de la actividad productiva ya existente en el seno de la propia empresa o consecuencia de fusiones o adquisiciones de empresas españolas, muy por delante de la constitución de nuevas sociedades. El hecho ha sido relacionado con la necesidad de ampliar las redes comerciales, la cuota de mercado o desde un proceso expansivo para competir en mejor posición con las empresas nacionales (Fernández-Otheo, 2004).

De la misma forma, hasta un $60,5 \%$ del total de inversión española en el extranjero en el periodo (245.000 millones de euros) tuvo su origen en la región madrileña. Las cifras más recientes confirman que Madrid ha mantenido su posición en el conjunto nacional, a pesar del frenazo vivido a comienzos de la década y que afectó con especial intensidad a la región, tanto en términos del flujo de entrada bruto, como del flujo de salida neto, una vez descontadas las desinversiones en el exterior (Jiménez, 2002).

Fijándonos en las características sectoriales del flujo de entrada, el que principalmente nos interesa aquí, se confirma el mantenimiento de la tradicional preferencia de la IED por el sector de servicios madrileño, reforzándose la tendencia general a la terciarización de la economía. En efecto, más del ochenta por ciento de la inversión se dirigió a actividades de servicios, destacando Transportes y Comunicaciones (44,20\% del total), Inmobiliarias y servicios a las empresas $(14,35 \%)$ y Actividades financieras (9,52\%), muy por delante del conjunto de la Industria extractiva y manufacturera $(12,55 \%)$.

Los datos históricos permiten observar el vuelco sectorial de las inversiones y el cambio de patrón dentro de las actividades de servicios experimentado desde la década pasada (Figura 1). De esta manera, si desde finales de los años ochenta y hasta mediados de los noventa se había observado un fuerte dinamismo por parte de los subsectores

de valores extranjeros (ETVE) controladas por residentes, ni las adquisiciones a no residentes, ni las reestructuraciones de grupos extranjeros. financiero y asegurador, lo sucedido con el sector de las Telecomunicaciones a comienzos de la actual década resulta espectacular. En relación con su fuerte dinamismo hay que recordar el goteo de medidas liberalizadoras que culmina en 1998 con la Ley General de Telecomunicaciones, año en el que la liberalización de la telefonía fija, unida a la ya existente de la telefonía móvil, produjo un efecto rápido de atracción de fuertes inversiones de grupos extranjeros. En este sentido, el hundimiento de la inversión tras los años 1999 y 2000 tuvo que ver con una importante disminución de la demanda, una vez que las redes de telefonía móvil y fija de los inversores extranjeros (Grupo Auna, Vodafone, Jazztel, Uni2 y Ono) ya estaban desplegadas.

Ese avance en la utilización de las tecnologías de la información y las comunicaciones habría propiciado, a su vez, la llegada de filiales de multinacionales para operar en actividades de servicios a empresas, en los que la utilización de esas tecnologías constituía uno de los pilares de su funcionamiento y en los que podían encontrar buenas cuotas de mercado (Fernández Fernández, 2000). Como quiera que muchas de estas empresas pertenecerían al terciario avanzado, hace tiempo que el comportamiento de la IED en Madrid se relacionó con la consolidación de una economía servindustrial, síntoma para algunos de que ya entonces estábamos ante una "ciudad rectora emergente” (Martín-Roda, 1997).

Todo lo anterior contrasta con la progresiva pérdida de protagonismo de la industria en los flujos de entrada de IED. La relativa falta de interés de los inversores extranjeros por la industria nacional en general ha sido relacionada con una reorientación de los flujos hacia países con costes de fabricación más reducidos; la caída reciente de la inversión estaría afectando a algunas manufacturas de elevada intensidad tecnológica, como la fabricación de material y equipo electrónico, muy destacadas en el pasado reciente de la región (Fernández-Otheo, 2004; Calatrava y Melero, 2007). En cualquier caso, tal como sugiere la información de la Figura 1, la evolución reciente de la industria no puede disociarse ya de la de los servicios a la producción.

Aunque no es el objetivo último del trabajo, parece oportuno cerrar el apartado de la interna- 
Figura 1. Evolución de la inversión extranjera directa en la Comunidad de Madrid, 1993-2006

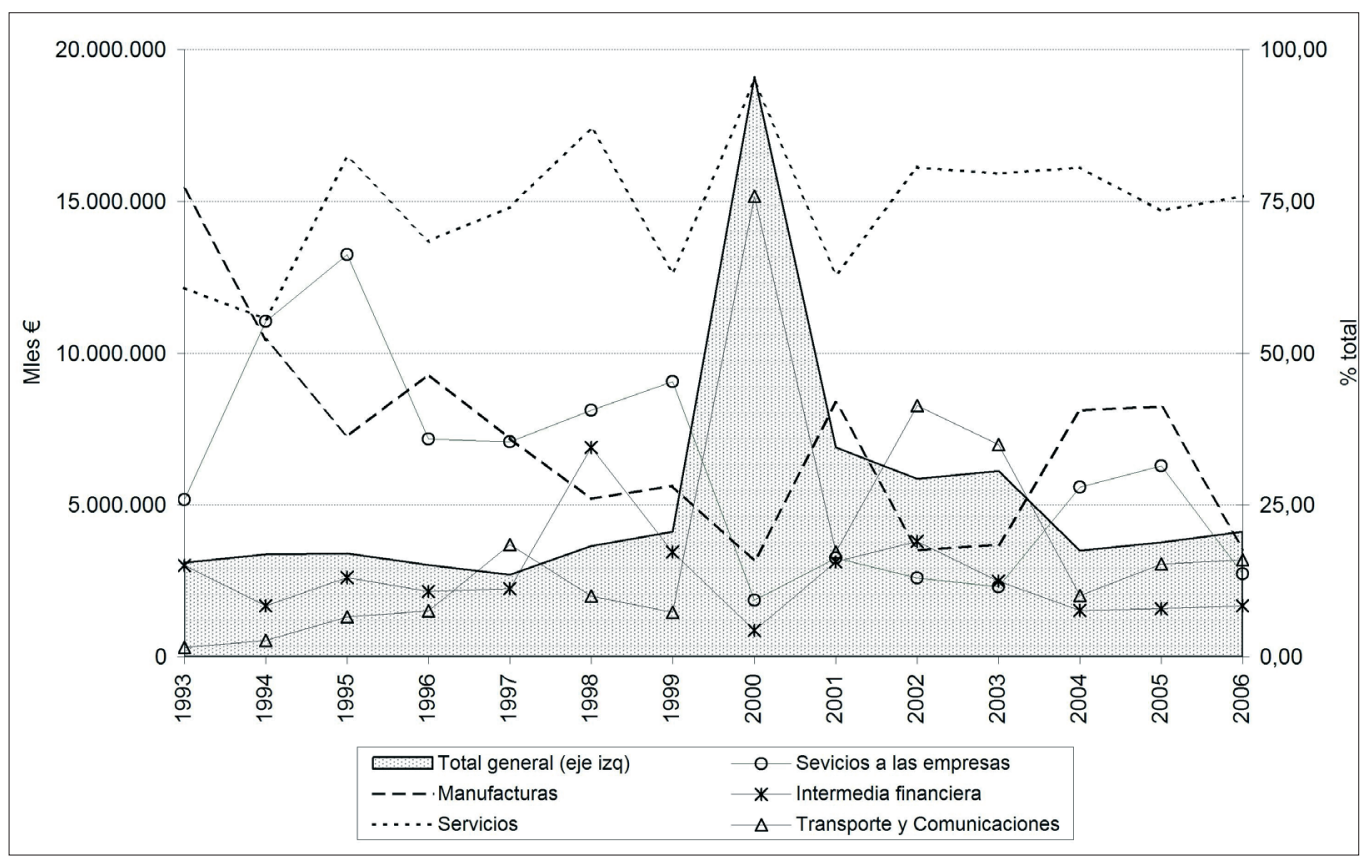

Fuente. Registro de Inversiones Exteriores.

cionalización recordando que esa fuerte orientación hacia las actividades de servicios se observa igualmente en el flujo de salida de la inversión con origen en la Comunidad de Madrid. Más de tres cuartas partes de la inversión de la región en el extranjero registrada entre 2000 y 2006 se destinó a alguna de las ramas de servicios, con un claro predominio de Transporte y Comunicaciones (50,16\% del total), seguido de Intermediación financiera (10,38\%) e Inmobiliarias y servicios a las empresas (7,24\%). Por destinos geográficos, estas inversiones se dirigieron, sobre todo, a nuevos países de la Unión Europea, reduciéndose progresivamente la tradicional hegemonía de América Latina, además de países del Magreb, a más distancia.

Sin perder de vista la gran visibilidad internacional que desde mediados de la década pasada han ido alcanzando grandes empresas de capital nacional con sede en la Comunidad de Madrid, como Telefónica o Repsol-YPF, resulta obligado ahondar en lo sucedido en el ámbito concreto de los servicios financieros y servicios avanzados a las empresas.

Tal como ha señalado recientemente la OCDE, gracias a las inversiones en países como México o Bra- sil por parte de dos grandes bancos con base en Madrid, el Banco Santander Central Hispano (BSCH) y el Banco Bilbao Vizcaya Argentaría (BBVA) ${ }^{4}$, en 2003 estas instituciones ya se situaban en los dos primeros puestos del ranking de los mayores bancos en Latinoamérica por activos consolidados $(62.894 \mathrm{y}$ 61.019 millones USD respectivamente), según datos de la Comisión Económica para América Latina y Caribe-CEPAL (OCDE, 2007).

Por su parte, entre los servicios a las empresas destacan empresas de seguridad, como los grupos Prosegur o Eulen, además de marketing, consultoría de ingeniería, etc. Al respecto, cabe recordar la importante actividad ferial de Madrid, desarrollando el IFEMA un tipo de servicio a la producción que hoy recibe la máxima atención por su contribución, entre otras cosas, como instrumento de marketing, fuente de información y conocimiento estratégico del sector, y su proceso de internacionalización en general. Sirva como muestra de esto último ese $22 \%$ de empresas

4 En el caso del BBVA la sede social permanece en la ciudad de Bilbao, aunque el resto de las funciones han sido trasladadas a Madrid. 
extranjeras, sobre un total de 40.081 empresas participantes en los 71 certámenes celebrados en 2005 (crecimiento del 60\% respecto de 2003), o el 10,8\% de visitantes alcanzados en 2004 , del total de visitantes contabilizados en el ámbito de los grandes centros europeos (EMECA), cifras que en definitiva confirman la rápida incorporación de Madrid al liderazgo ferial internacional (Rubalcaba Bermejo, 2006).

\section{Los grupos internacionales de empresas en la Comunidad de Madrid.}

La llegada de esos importantes flujos de inversión, materializados a través de la creación de filiales, la participación en grupos de empresas, la adquisición de empresas españolas, por fusiones o mediante otros tipos de aportaciones a las mismas, estaría directamente relacionada con la amplia presencia de empresas multinacionales en España y en la Comunidad de Madrid. De acuerdo con el DIRCE, a fecha de 1 de enero de 2002 existían en el conjunto del país un total de 21.654 unidades con personalidad jurídica, que actúan bajo estrategia de grupos internacionales de empresas; pese a representar solo el 0,8\% del total de empresas españolas, contribuyen con más de la mitad del total de facturación (Instituto Nacional de Estadística, 2003).

Cuadro 1. Los grupos internacionales de empresas en la Comunidad de Madrid, 2002.

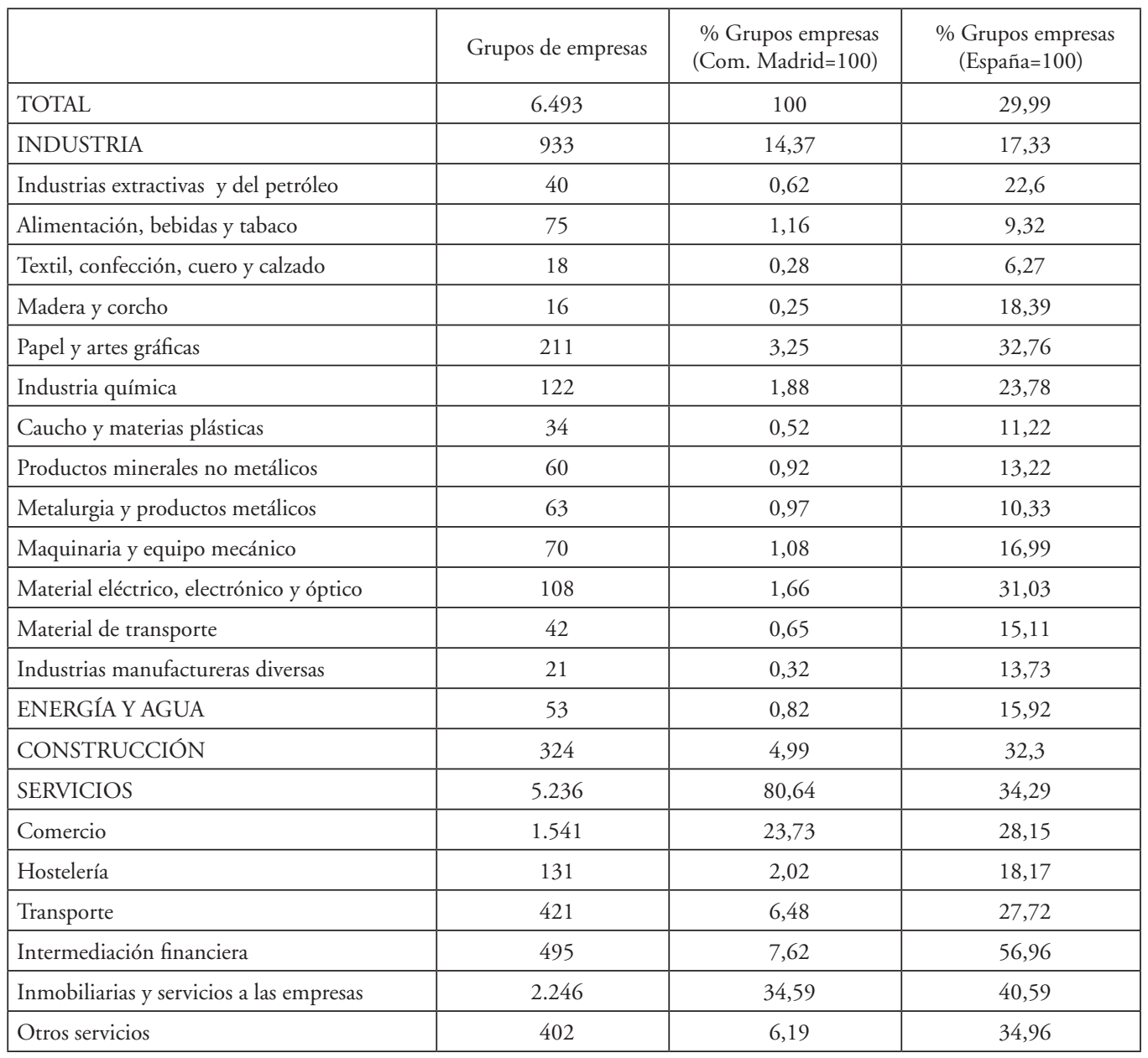

Fuente. Elaboración propia. 
Hasta un 30\% de estas empresas pertenecientes a grupos internacionales se localiza en la Comunidad de Madrid (6.493 empresas), superando en algo más de un punto a Cataluña, y muy por encima en cualquier caso de lo observado en el resto del país. De acuerdo con su estructura sectorial (Cuadro 1), la concentración de grupos de empresas en la región resulta especialmente acusada en los servicios, concretamente en Intermediación financiera $(56,96 \%$ del total nacional) e Inmobiliarias y servicios a las empresas $(40,59 \%)$, por delante de Construcción $(32,30 \%)$ e Industria $(17,33 \%)$. Dentro de este último sector destacan algunas ramas concretas como Papel y Edición (32,76\%) o Material y Equipo eléctrico y electrónico $(31,03 \%)$.

$\mathrm{Al}$ mismo tiempo, tomando como referencia la propia economía regional, resulta evidente la orientación hacia dos grandes tipos de actividades, las Inmobiliarias y servicios a las empresas y el Comercio, que representan en conjunto casi el $60 \%$ de todas las empresas en grupos de la región. En este sentido, aunque en general las ramas de servicios concentran un mayor volumen, dada la intensa terciarización de la economía madrileña su peso se diluye dentro de los respectivos sectores. Esto no sucede en muchas de las ramas industriales, en especial Industria Química, Industrias extractivas y del petróleo o Material de transporte, donde la presencia de grupos llega a rozar en ocasiones el 20\% del total de empresas registradas en el DIRCE.

Al hilo de la novedosa información sobre los grupos internacionales de empresas se hace necesaria una aclaración en relación con el aparente equilibrio entre las preferencias de localización en la Comunidad de Madrid y en Cataluña, región que alberga a Barcelona, segunda metrópoli del país y competidora directa dentro del sistema urbano español e internacional. Tres hechos matizan el significado de las cifras aportadas:

En primer lugar, hay que aludir a los contrastes en la estructura territorial de ambas regiones metropolitanas, ya que en el caso de la Comunidad de Madrid hablamos de grupos de empresas mayoritariamente localizados en la ciudad central, mientras que en Cataluña crece el peso de las localizaciones alternativas a Barcelona.

Sin perder de vista ese hecho, se confirma la polarización hacia Madrid de los grupos interna-

Figura 2. Porcentaje de grupos internacionales de empresas en la Comunidad de Madrid y en Cataluña según sectores de actividad, 2002

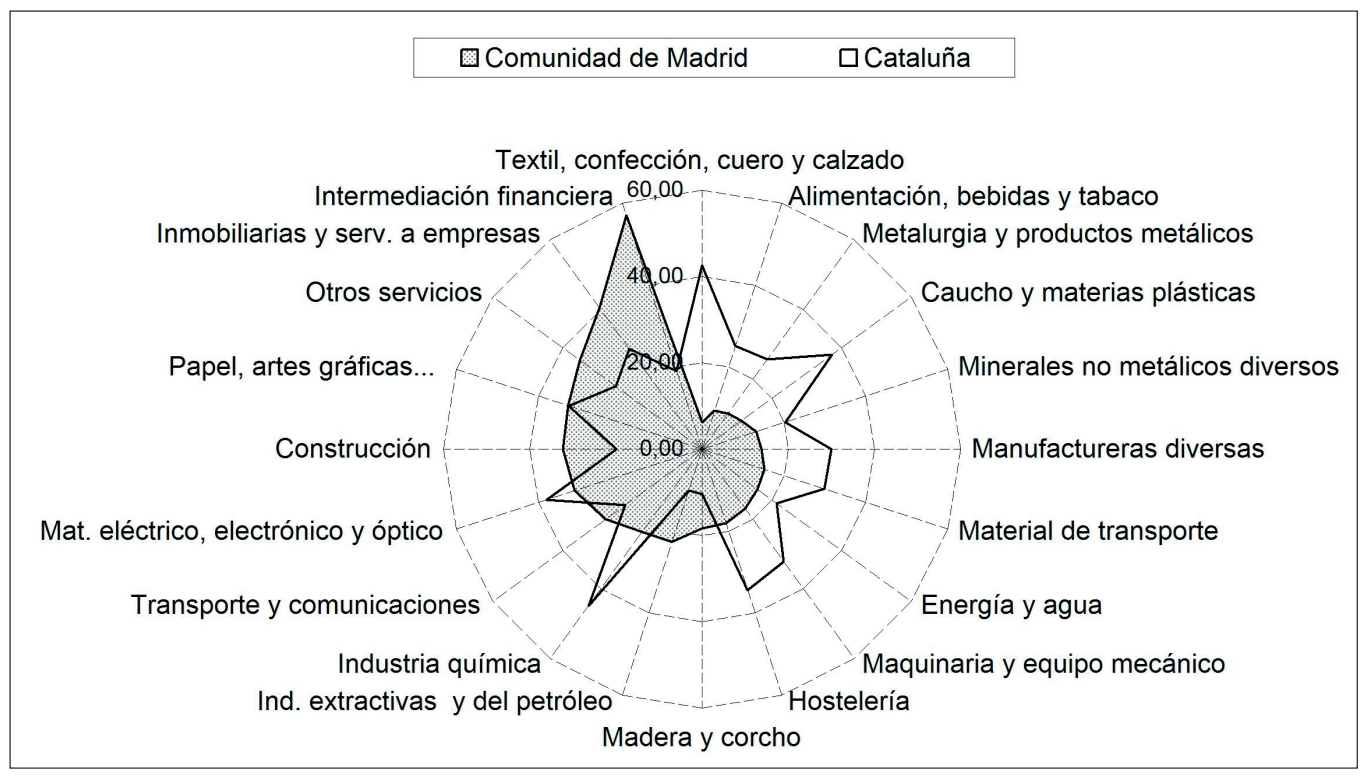

Fuente. Elaboración propia. 
cionales en actividades terciarias avanzadas, incluida la intermediación financiera (Figura 2). Por su parte, la Comunidad Catalana atraería un mayor porcentaje en la mayoría de las ramas manufactureras, a excepción de algunas pocas actividades beneficiadas por el efecto sede en la capital madrileña (Industrias extractivas y del petróleo, Madera y Corcho...) o que integran algunos de los clusters industriales más representativos de Madrid en la última década, como Artes Gráficas y Material Electrónico (Sánchez Moral, 2006).

Finalmente, los datos sobre la presencia de grupos de empresas en ambas regiones españolas no permiten observar los contrastes que al respecto surgen de la comparación de los tamaños de las empresas, independientemente de su pertenencia o no a grupos internacionales. Así por ejemplo, según el DIRCE, la Comunidad de Madrid concentraría hasta 266 de las 500 mayores empresas de España con más de 1.000 trabajadores, mientras que en Cataluña se localizan 109, confirmándose las preferencias de las grandes empresas multinacionales, de capital nacional o extranjero, por localizarse en la región.

\section{Características de las empresas extranjeras en la ciudad de Madrid.}

La base de datos $\mathrm{SABI}^{5}$ contiene la información económico-financiera de más de 200.000 empresas españolas (el 95\% de todas las empresas españolas con facturación superior a los 360.000 euros y obligadas, por tanto, a presentar sus cuentas en los registros mercantiles). A partir de este universo, a través del estudio de la estructura del accionariado fueron seleccionadas aquellas empresas en las que más del $50 \%$ de su capital resultaba no ser nacional, considerándolas a todos los efectos como empresas extranjeras.

De acuerdo con la información del Cuadro 2, en la ciudad de Madrid se localizan en 2006 un total de 2.636 empresas con predominio de capital extranjero, lo que representa más del $70 \%$ de todas las localizados en la Comunidad de Madrid y más de la cuarta parte de todas las existentes en el conjunto del país (cuando en la ciudad de Barcelona

Bureau van Djik Electronic Publishing S.A. se roza el $15 \%$ del total nacional y el $50 \%$ de las empresas extranjeras de la provincia). Las empresas extranjeras cuyo domicilio social se localiza en Madrid tendrían un tamaño medio en torno a los 155 trabajadores, por encima de lo observado en el conjunto del país y en la ciudad de Barcelona, aunque algo por debajo de la propia región de Madrid, mientras que la ratio de ingresos medios por empleado, sobre los 153.000 euros, resulta muy superior al valor en todas las distribuciones de referencia. Por otro lado, el estudio de las fechas de creación de las empresas revela que se trata de un tejido empresarial relativamente joven, creado sobre todo en la década de los noventa, si bien la aparición de empresas extranjeras comienza a ser considerable desde la década de los setenta.

En cuanto a las diferencias que respecto de estos parámetros básicos se observan entre las empresas extranjeras y las nacionales dentro del sector industrial (mucho más estudiado), cabe señalar que las primeras presentan un tamaño medio diez veces superior, una cifra de ingresos de explotación casi nueve veces mayor y una ratio ingresos por empleado que triplica la de las nacionales, confirmándose esto en todos los niveles de intensidad tecnológica (Calatrava \& Melero, 2007). En este sentido, la evidencia acerca de la mayor eficiencia técnica de las empresas extranjeras respecto de las nacionales ha sido atribuida, sobre todo, a las características de los procesos, recursos humanos y tecnologías de las empresas; así, una vez controlados estos aspectos, las ventajas asociadas a la propiedad del capital (aprovechamiento de experiencia previa en otros mercados, transmisión de información, sinergias en la actividad internacional, etc.) y a la vocación exportadora resultan ser factores menos determinantes de cara a explicar las diferencias de eficiencia (Merino de Lucas \& Salas Fumás, 1996).

El Cuadro 3 recoge la distribución por actividades de las empresas extranjeras, lo cual incide directamente sobre las mencionadas características. Aprovechando el mayor grado de desagregación sectorial y espacial de la fuente, observamos la capacidad de atracción ejercida sobre una serie de actividades que se acercan o incluso superan el $50 \%$ de concentración nacional en la ciudad de Madrid, como Intermediación financiera 
Cuadro 2. Empresas con más del 50 por ciento de participación extranjera en su capital, 2006

\begin{tabular}{|l|c|c|c|c|}
\hline & No Empresas & $\%$ & Tamaño medio & $\begin{array}{c}\text { Ingresos medio } \\
\text { por empleado }(€)\end{array}$ \\
\hline Ciudad de Madrid & 2.636 & 26,15 & 155,88 & $159.933,68$ \\
\hline Comunidad de Madrid & 3.744 & 37,14 & 166,29 & $153.067,70$ \\
\hline Barcelona & 1.469 & 14,57 & 92,37 & $49,86,34$ \\
\hline España & 10.081 & 100 & 122,37 & $124.024,16$ \\
\hline
\end{tabular}

Fuente. Elaboración propia a partir de SABI.

(54,29\%), Actividades informáticas (51,51\%) u Otras actividades empresariales (44,40\%). Muchas otras actividades superan holgadamente el veinte por ciento, empezando por Transporte y Comunicaciones $(29,61 \%)$, Construcción $(27,50 \%)$ o Comercio (22,16\%), al tiempo que la mayor parte de las ramas industriales se sitúa por debajo de dicho porcentaje, a excepción de nuevo del Papel y Edición (34,41\%) e Industrias extractivas y del petróleo $(25,00 \%)$.

De forma coherente con las anteriores fuentes, los datos de SABI vienen a confirmar que más del $85 \%$ de todas las empresas extranjeras de la ciudad se dedican a alguna de las ramas de servicios. Más aún, si consideramos conjuntamente aquellas tres que integran los servicios a las empresas (Actividades informáticas, Investigación y desarrollo y Otras actividades empresariales), con un 28,27\% del total, se convierten en el grupo de empresas extranjeras con mayor peso en la economía de la ciudad, seguido de Comercio (26,78\%), Actividades inmobiliarias $(12,25 \%)$ y financieras $(6,49 \%)$. En relación con estas últimas actividades, el caso de Madrid resulta excepcional dadas las especiales características del sistema financiero español, adaptado durante décadas al entorno protegido de la economía española y por tanto con limitada apertura a la banca extranjera, aunque hoy en día en plena transformación ante las tendencias generales de liberalización, concentración e internacionalización que sacuden el sector a escala mundial (García Delgado, 2003).

De acuerdo con la mencionada comparativa, planteada también a partir del SABI, aunque el capital nacional domina en todos los subsectores industriales (cuyos pesos están en todo caso muy por debajo de lo observado entre los servicios), la presencia relativa de empresas extranjeras resultaría más significativa en actividades como Tabaco (50\% de las empresas del sector), Vehículos de motor $(39,5 \%)$, Industria química $(20,1 \%)$, Metalurgia $(19,6 \%)$, Otro material de transporte $(17,1 \%)$, Material electrónico $(16,3 \%)$ o Industrias del Petróleo (14,3\%). Al respecto conviene recordar que las tareas de producción de la mayoría de estas empresas extranjeras no tienen efecto en la ciudad, por lo que estas cifras reflejan el comentado fenómeno de atracción de sedes sociales hacia la metrópoli madrileña. Este comentario, que se hace extensivo a las empresas nacionales radicadas en la ciudad, no es aplicable a las empresas localizadas en otros municipios de la región, donde muchas empresas extranjeras todavía desarrollan actividades de producción (Calatrava \& Melero, 2007).

\section{La concentración sectorial y espacial de las funciones comando en la metrópoli madrileña.}

Pese a la trascendencia que a escala nacional adquiere el sector financiero de Madrid (en términos de concentración de la banca extranjera y banca de negocios, servicios de intermediación financiera, volumen de contratación de la bolsa, etc.), lo que le ha valido la consideración de plaza financiera europea por detrás solo de Londres, París y Frankfurt, lo cierto es que la concentración de funciones comando no se agota en los servicios de intermediación financiera. Nuestros datos confirman que la concentración de empresas extranjeras en servicios a las empresas avanzados, del que la intermediación financiera no sería sino otro más, resulta especialmente acusada en la metrópoli madrileña. A esto habría que sumar las empresas de capital nacional en dichos sectores y, según lo explicado, funciones avanzadas que se 
Cuadro 3. Empresas extranjeras de la ciudad de Madrid según actividad principal, 2006

\begin{tabular}{|c|c|c|c|c|}
\hline & $\begin{array}{l}\text { Numero de } \\
\text { empresas }\end{array}$ & $\%$ & $\begin{array}{l}\text { \% empresas } \\
\quad(\text { Com. } \\
\text { Madrid=100) }\end{array}$ & $\begin{array}{r}\% \text { empresas } \\
(\text { España }=100)\end{array}$ \\
\hline TOTAL & 2.636 & 100,00 & 70,41 & 26,15 \\
\hline AGRICULTURA & 17 & 0,64 & 73,91 & 16,50 \\
\hline INDUSTRIA & 279 & 10,58 & 59,62 & 13,60 \\
\hline Industrias extractivas y del petróleo & 16 & 0,61 & 88,89 & 25,00 \\
\hline Alimentación, bebidas y tabaco & 25 & 0,95 & 64,10 & 12,20 \\
\hline Textil, confección, cuero y calzado & 9 & 0,34 & 90,00 & 11,69 \\
\hline Madera y corcho & 0 & 0,00 & 0,00 & 0,00 \\
\hline Papel y artes gráficas & 64 & 2,43 & 73,56 & 34,41 \\
\hline Industria química & 47 & 1,78 & 51,65 & 13,51 \\
\hline Caucho y materias plásticas & 3 & 0,11 & 21,43 & 1,78 \\
\hline Minerales no metálicos diversos & 20 & 0,76 & 86,96 & 15,87 \\
\hline Metalurgia y productos metálicos & 23 & 0,87 & 69,70 & 11,17 \\
\hline Maquinaria y equipo mecánico & 17 & 0,64 & 42,50 & 8,59 \\
\hline Material eléctrico, electrónico y óptico & 30 & 1,14 & 46,88 & 16,22 \\
\hline Material de transporte & 19 & 0,72 & 54,29 & 9,31 \\
\hline Industrias manufactureras diversas & 6 & 0,23 & 66,67 & 11,32 \\
\hline ENERGÍA Y AGUA & 23 & 0,87 & 88,46 & 19,49 \\
\hline CONSTRUCCIÓN & 55 & 2,09 & 75,34 & 27,50 \\
\hline SERVICIOS & 2.262 & 85,82 & 71,72 & 29,73 \\
\hline Comercio & 706 & 26,78 & 57,63 & 22,16 \\
\hline Hostelería & 36 & 1,37 & 80,00 & 19,89 \\
\hline Transporte y Comunicaciones & 159 & 6,03 & 69,43 & 29,61 \\
\hline Intermediación financiera & 171 & 6,49 & 89,53 & 54,29 \\
\hline Actividades inmobiliarias & 323 & 12,25 & 84,78 & 22,81 \\
\hline Alquiler de maquinaria y equipo sin operario & 31 & 1,18 & 50,00 & 27,19 \\
\hline Actividades informáticas & 205 & 7,78 & 78,54 & 51,51 \\
\hline Investigación y desarrollo & 5 & 0,19 & 55,56 & 20,83 \\
\hline Otras actividades empresariales & 535 & 20,30 & 84,38 & 44,40 \\
\hline Otros servicios & 91 & 3,45 & 77,78 & 39,22 \\
\hline
\end{tabular}

Fuente. Elaboración propia a partir de SABI.

desarrollan en el interior de las sedes centrales de las empresas en general $^{6}$.

\footnotetext{
Según estimaciones de la Comunidad de Madrid, la región concentraría a 144.265 trabajadores vinculados a los servicios centrales de dirección y administración dentro de las empresas, el 68,46\% del total nacional. Estos servicios centrales aportarían al VAB regional unos 13.149 millones de euros, el $77,21 \%$ del valor generado por estos servicios en el conjunto del país (Ayet y Sanz, 2004).
}

Tomando como referencia la Clasificación Nacional de Actividades Económicas, si excluimos las actividades inmobiliarias y de alquiler (CNAE 70 a 71), así como los servicios a las empresas considerados banales, es decir, selección de personal, seguridad, limpieza y actividades empresariales diversas (CNAE 745 a 748), obtenemos una imagen más precisa de los servicios a las empresas avanzados, al que pertenecerían hasta 572 empre- 
Cuadro 4. Características de las empresas de la ciudad de Madrid, 2006

\begin{tabular}{|l|c|c|}
\hline & Extranjeras & Nacionales \\
\hline Intermediación financiera & 171 & 3.989 \\
\hline Servicios avanzados a empresas & 572 & 14.406 \\
\hline - Tamaño medio & 77,00 & 18,00 \\
\hline - Ingresos medios por empleado & 170,86 & 116,84 \\
\hline - \% con actividad exterior & 46,31 & 17,40 \\
\hline - \% creadas desde 2000 & 38,17 & 41,01 \\
\hline
\end{tabular}

Fuente. Elaboración propia a partir de SABI.

sas extranjeras, superando ampliamente las $171 \mathrm{de}$ intermediación financiera, y representando más del $76 \%$ del total de los servicios empresariales (Cuadro 4). La comparativa con el capital nacional dentro del grupo de los servicios avanzados a las empresas, confirma que su presencia se diluye dentro de la terciarizada economía madrileña (en media representan en torno al $4 \%$ del total). Se trata de un tejido empresarial joven (al igual que las nacionales); prácticamente la mitad de las empresas se constituyeron durante los años noventa y hasta un 38\% después del año 2000. Aunque sin llegar a los extremos de la industria, el tamaño medio resulta muy superior a las nacionales (77 frente a 18 empleados), lo mismo que los ingresos medios por empleado (170.86 frente a 116.84 miles de euros), o el porcentaje de las que tienen alguna actividad exterior $(46,31 \%$ frente a $17,4 \%$ en promedio).

Muchos de esos contrastes sin duda aluden a la presencia en la ciudad de Madrid de grandes oficinas, por encima de los mil trabajadores, pertenecientes a empresas extranjeras de consultoría informática o de negocios (entre otras, IBM Global Services, Atos Origin, Accenture, GTronics, Ernst \& Young o Price Waterhouse) y cuyo protagonismo resulta máximo desde la perspectiva de esas redes internacionales de oficinas dedicadas a los llamados "servicios globales", como contabilidad y auditoria, publicidad, banca e intermediación financiera o servicios jurídicos, esenciales para la gestión y coordinación de sistemas económicos globales (Beaverstock et al., 2000; Taylor, Walter \& Beaverstock, 2002).
De esta manera, si observamos la estructura de los servicios avanzados (Figura 3), comprobamos que los grupos más numerosos corresponden a Otras actividades informáticas, seguido de Publicidad, Gestión de sociedades de cartera (Holdings), Consulta de aplicaciones informáticas, y Consulta y asesoramiento sobre dirección y gestión empresarial, a lo que habría que añadir las actividades de intermediación financiera, que en conjunto representan menos de la cuarta parte del total. A todas estas actividades se dedican también multitud de empresas nacionales, si bien en este caso el mayor peso corresponde a los Servicios técnicos de arquitectura e ingeniería, Contabilidad y $\mathrm{Pu}$ blicidad. Si, como vimos, la presencia del capital extranjero dentro de los servicios avanzados se sitúa alrededor del $4 \%$, su peso aumentaría en los diversos servicios informáticos, por un lado, y en la Gestión de sociedades de cartera (Holdings), por otro; mientras que en otras muchas actividades, como contabilidad, asesoría jurídica o servicios técnicos, su presencia resulta en cambio comparativamente menor.

Concluimos el análisis haciendo referencia a la geografía del capital extranjero en la región, marcada por una acusadísima concentración en la ciudad central, en especial del llamado terciario direccional; un aspecto clave en relación con la configuración de la metrópoli madrileña, la especialización funcional del espacio central y sus procesos recientes de transformación, tanto de naturaleza económica como social (Estébanez, Molina \& Pérez Sierra, 1993; Molina Ibáñez \& Martín-Roda, 1998; Méndez, 2001). 
Figura 3. Porcentaje de empresas de la ciudad de Madrid en funciones comando, según origen del capital en 2006

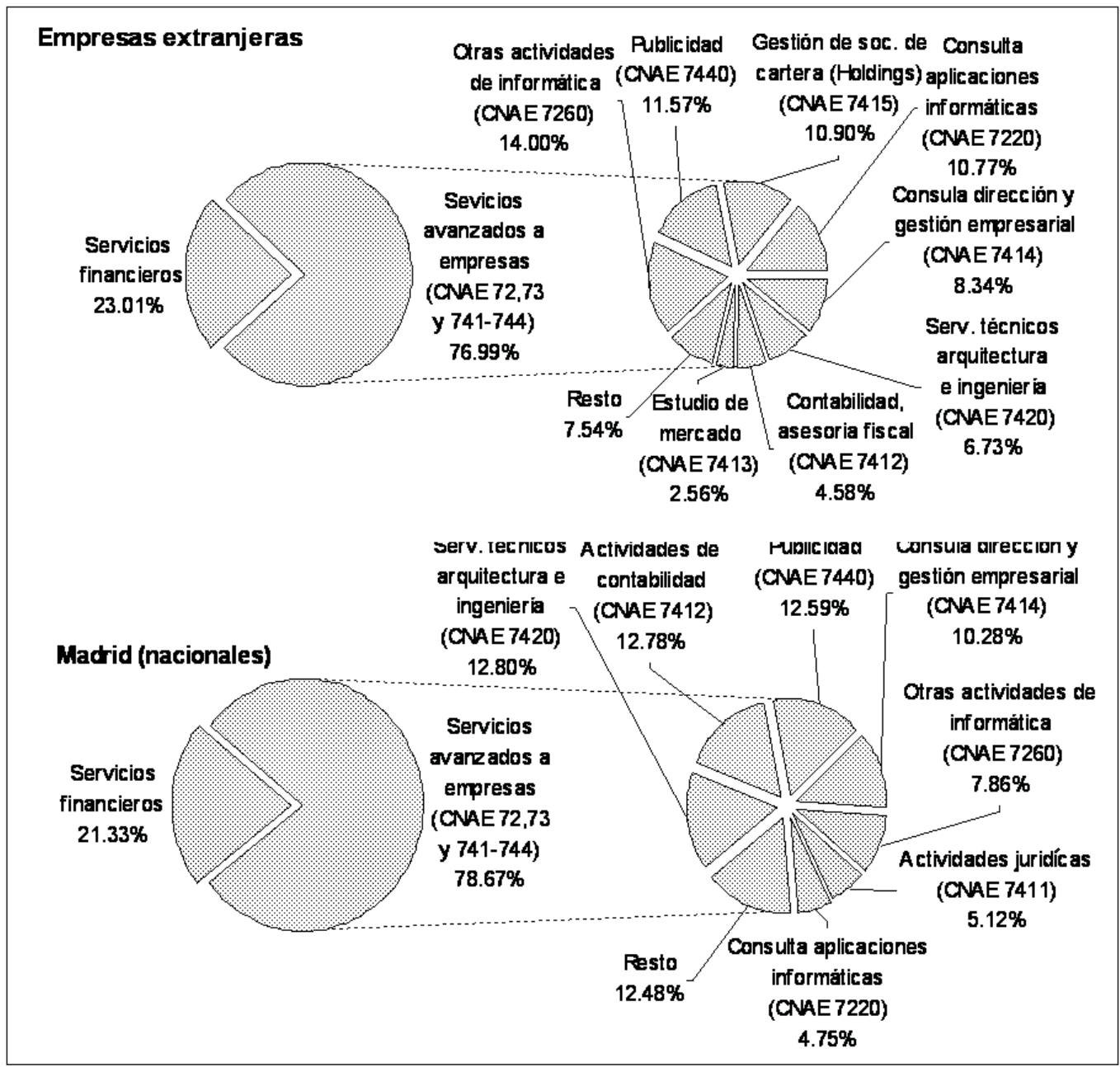

Fuente. Elaboración propia a partir de SABI.

Como vimos, de las 3.744 empresas extranjeras existentes en la región, hasta un 70,50\% tiene su domicilio social en la ciudad de Madrid, distribuyéndose el resto entre 61 municipios de la región, destacando algunos núcleos del área metropolitana que superan las 50 empresas extranjeras, como Alcobendas, Las Rozas de Madrid, Tres Cantos, Pozuelo de Alcorcón, San Sebastián de los Reyes, etc.

Se confirma, en ese sentido, que las decisiones de localización de las empresas extranjeras refuerzan las tendencias y desequilibrios generados por la desigual distribución en el territorio madrileño de las empresas en general. No parece, por tanto, que el origen del capital sea en principio la variable más determinante, sino más bien el sector de actividad; en un contexto general de fuerte concentración espacial, la distribución de las empresas extranjeras dedicadas a actividades industriales presenta un grado de polarización sensiblemente más bajo (el peso de la capital desciende hasta el $60 \%$ ), reflejo de los procesos de descentralización y difusión espacial vividos desde hace décadas en la región.

Por el contrario, tal como refleja el mapa A de la Figura 4, la polarización de las empresas extran- 
Simón Sánchez Moral, Ascensión Calatrava Andrés y Ana Melero Guilló

Figura 4. Distribución de las empresas extranjeras en sectores comando en la metrópoli madrileña, 2006
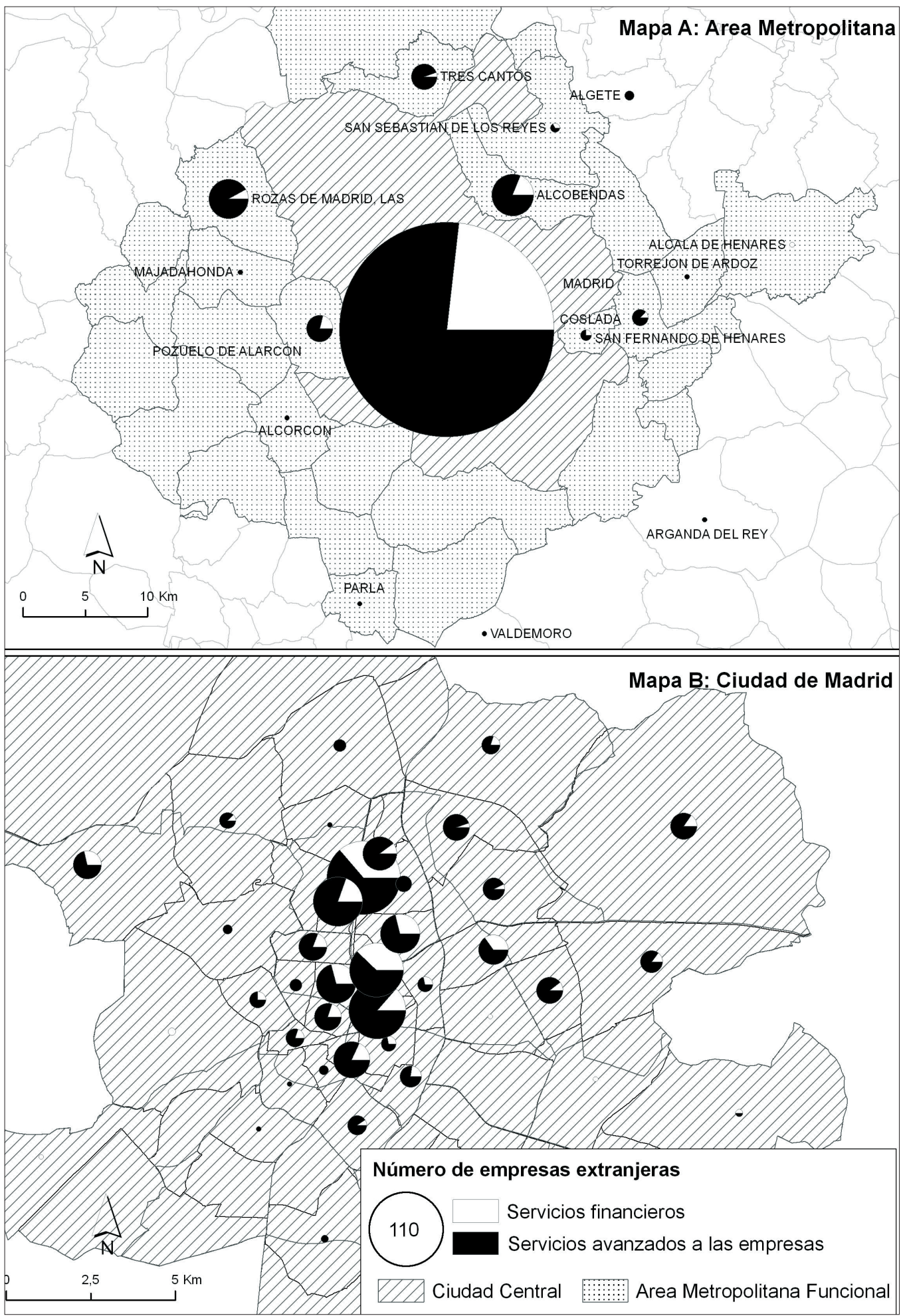

Fuente. Elaboración propia. 
jeras en servicios financieros y servicios avanzados crecería de forma dramática en la ciudad central $(89,59 \%$ y $82,41 \%$ del total regional respectivamente), al encontrar allí las máximas ventajas de localización asociadas a la centralidad, la existencia de un entorno de negocios de elevada densidad que favorece los contactos cara a cara y espacios urbanos de elevada calidad y representatividad. Al mismo tiempo, se observa cierto retroceso del peso de los núcleos del llamado Corredor del Henares, al este de la capital (tradicionalmente más diversificados, sobre todo por la presencia de actividades industriales y de distribución), manteniéndose en cambio el de unos pocos en la zona norte metropolitana (como Tres Cantos y Alcobendas) y oeste (como Pozuelo de Alarcón y Las Rozas). Nos encontramos, en efecto, ante dos de los ámbitos metropolitanos más dinámicos, beneficiados por una relativa centralidad dentro de la metrópoli y al mismo tiempo una elevada calidad medio-ambiental y de las infraestructuras, y una oferta muy atractiva de espacios para actividades económicas en constante renovación, que incluye modernos parques empresariales y de oficinas, parques tecnológicos, etc.

En el interior de la ciudad de Madrid se observa el mismo patrón de concentración espacial (Figura 4, mapa B), de tal forma que tan solo siete distritos postales de la capital concentran casi el 55\% de las empresas extranjeras dedicadas a los sectores comando, apareciendo las mayores concentraciones a lo largo del eje del Paseo de la Castellana, donde destacan AZCA y Cuzco, los dos principales centros de negocios madrileños. En relación con este eje norte, que se proyectaría más allá de los limites municipales para unirse con los espacios metropolitanos descritos arriba, debemos mencionar algunos proyectos urbanos muy importantes, llamados a acoger en los próximos años buena parte del terciario direccional de la ciudad, como las torres de la antigua ciudad deportiva del Real Madrid (Cuatro Torres Business Area-CTBA), la ciudad de Telefónica (Distrito C) o la futura ciudad financiera del Banco Bilbao Vizcaya Argentaria.

En el tramo central del Paseo de la Castellana la concentración se extiende a ambos lados, en especial hacia uno de los barrios residenciales de más alto estanding de la ciudad, el de Salamanca, para descender progresivamente hasta la zona de Recoletos-Paseo del Prado (en cuyo entorno se localiza la Bolsa de Madrid). Fuera de aquí destaca el eje que en dirección este conecta el centro de la ciudad con la zona del Aeropuerto Internacional Madrid-Barajas (que lógicamente adquiere una enorme trascendencia desde la perspectiva de la atracción de capital extranjero), así como una concentración secundaria en el extremo occidental del municipio.

Por otro lado, en cuanto al reparto entre servicios financieros y servicios avanzados cabe señalar que en el conjunto de la región el peso de los primeros se sitúa en torno a un $22 \%$ (frente al 78\% de los servicios avanzados a las empresas), creciendo en la capital y en algunos municipios adyacentes, confirmando el criterio de centralidad. Dentro de la ciudad destaca su peso relativo en el eje de la Castellana y la zona de conexión con el Aeropuerto; solo en estos dos ámbitos de la capital se localiza prácticamente el $40 \%$ de las empresas extranjeras en servicios financieros de la región.

\section{Conclusiones.}

Procesos vinculados a la globalización y al cambio tecnológico, como la terciarización económica o la fragmentación productiva, son aludidos de forma habitual para explicar el dinamismo económico de la metrópoli de Madrid y su intensa transformación territorial en las últimas décadas. Pero como en otras grandes metrópolis, la controversia "ciudad global versus ciudad capital" (política, económica o cultural) no termina con la discusión sobre el origen del crecimiento urbano observado; supone adentrarse en el modo de articulación de la metrópoli con el estado y la economía nacional, y, por tanto, en la forma y los contenidos de la nueva gobernanza urbana (Brenner, 1998; Gordon, 2006).

De esta manera, desde el argumento de sus necesidades y amenazas en tanto que ciudad global, Madrid demanda hoy competencias y recursos extraordinarios, por ejemplo para acometer infraestructuras complejas que tratan de evitar estrangulamientos en ese crecimiento (reciente ampliación del Aeropuerto Madrid-Barajas, soterramiento de 
la M-30, etc.), destacando en este sentido la nueva ley de capitalidad (Ley de Régimen Especial de la Ciudad de Madrid, de 2006).

A pesar del claro posicionamiento institucional, al revisar los numerosos trabajos científicos publicados en la última década se evidencia cierta ambigüedad en los criterios utilizados a la hora de dilucidar si Madrid puede ser considerada una ciudad global. Esto ha llevado a plantear aquí la revisión del debate teórico internacional, con el fin de orientar el análisis a la luz del concepto de ciudad global más extendido, en relación con la concentración de las funciones centrales o de comando necesarias para la gestión y coordinación de sistemas económicos globales.

El análisis de los datos sobre los flujos de IED, así como de la novedosa información sobre los grupos internacionales de empresas y las características de las empresas extranjeras, ha confirmado la elevada capacidad de atracción del capital extranjero por parte de la metrópoli madrileña, con una clarísima orientación hacia los servicios avanzados a las empresas, incluido el financiero. Ahora bien, tal como señalan los últimos debates teóricos, la construcción de la ciudad global es un proceso que solo puede ser entendido en el contexto de la red global de metrópolis. Se perfila así una agenda de investigación a futuro, donde la cuestión de las funciones comando de Madrid debe ser analizada en relación con el resto de las ciudades (empezando por la propia metrópoli catalana), tratando de incorporar, en la línea de lo sugerido por la red de investigación del GaWC, indicadores que permitan superar la descripción de determinados atributos para capturar a continuación las conexiones y relaciones que se establecen dentro de ese sistema de ciudades globales.

\section{Referencias bibliográficas}

Ayet, G.C. \& Sanz, B. (2004). Las sedes centrales en la economía madrileña. Madrid: Comunidad de Madrid.

Bagchi-Sen, S. \& Sen, J. (1997). The current state of knowledge in internacional business in producer services. Enviroment and Planning A, 29, 1153-1174.

Beaverstock, J.V., Simth, R.G., Taylor, P.J., Walker, D.R.F. \& Lorimer, H. (2000). Globalization and world cities: some measurement methodologies. Applied Geography, 20, 43-63.

Beaverstock, J.V., Simth, R.G. \& Taylor, P. J. (2000). World city network: A new metageography?. Annals of the Association of American Geographers, 90, 1, 123-134.

Boddewyn, J.J., Halbrich, M.B. \& Perry, A.C. (1985). Service multinationals: conceptualization, measurement and theory. Journal of International Business Studies, 17, 3, 41-57.

Brenner, N. (1998). Global cities, glocal states: global city formation and state territorial restructuring in contemporary Europe. Review of International Political Economy, 5, 1, 1-37.

Calatrava Andrés, A. \& Melero Guilló, A. (2007). La internacionalización de la empresa multinacional en España: la ciudad de Madrid como polo de atracción de empresas industriales. En A. Calatrava, S. Marcu, A. Melero \& R. Méndez (Eds.), Economias, mercados de trabajo y territorios metropolitanos en transformación (pp. 43-65). Madrid: Red ARETHUSE.

Castells, M. (1989). The informational city. London: Blackwell.

(1996). The rise of the network society. Oxford: Blackwell.

Ciccolella, P. (1999). Globalización y dualización en la Región Metropolitana de Buenos Aires: grandes inversiones y reestructuración socioterritorial en los años noventa. EURE, 25, 76, 5-27.

Cuadrado-Roura, J.R. \& Rubalcaba Bermejo, L. (2000). Los servicios a empresas como actividad estratégica en la economía española. Información Comercial Española, 787, 53-68.

Daniels P.W. \& Bryson, J.R. (2002). Manufacturing services and servicing manufacturing: knowledge-based cities and changing forms of production. Urban Studies, 39, 5-6, $977-$ 991.

De Mattos, C. (1999). Santiago de Chile, globalización y expansión metropolitana: lo que existía sigue existiendo. EURE, 25, 76, 29-56.

(2002). Transformación de las ciudades latinoamericanas: ¿impactos de la globalización? EURE, 28, 85, 5-10.

Dunning, J.H. (1979). Explaining changing patterns of international production: in defence of the eclectic theory. Oxford Bulletin of Economics and Statistic, 41, 4, 269-295. 
(1985). Multinational enterprises, economic structure and internacional competitiveness. Chichester: John Willey \& Sons.

Estébanez, J., Molina, M. \& Pérez Sierra, C. (1993). Madrid, configuración de una ciudad global. Geographicalia, 30, 177-190.

Fernández Fernández, M.T. (2000). Presencia y efectos de arrastre de las filiales extranjeras de servicios a empresas en España. Documento de Trabajo 1/2000. Madrid: SERVILAB, Universidad de Alcalá.

Fernández-Otheo, C.M. (2004). La internacionalización de la economía de Madrid. Economistas, 100, 337-343.

Friedmann, J. (1986). The world city hypothesis. Development and Change, 17, 69-83.

Friedmann, J. \& Wolff, G. (1982). World city formation: an agenda for research and action. Internacional Journal of Urban and Regional Research, 3, 309-344.

García Delgado, J.L. (dir.) (2003). Estructura económica de Madrid (2a Ed.). Madrid: Civitas.

Gordon, I. (2003). Capital needs, capital growth and global city rhetoric in Mayor Livingstone's London Plan. Ponencia presentada en 99th Annual Meeting of the Association of American Geographers, 7 de Marzo, 2003, New Orleans.

Illeris, S. (1997). Localización de los servicios a empresas en zonas urbanas y regionales. Economía Industrial, 313, 93-103.

Instituto Nacional de Estadística, INE (2003). Los grupos de empresas del DIRCE; Análisis de la globalización bajo la óptica de los registros de empresas. Resultados Estadisticos 2002. Madrid: Autor.

Jiménez, J. C. (2002). Madrid y los flujos de capital: al compás internacional. Economistas, 91, 407-412.

Knox, P. \& Taylor, P.J. (1995). World cities in a world system. Cambridge: Cambridge University Press.

Martínez, S.R. \& Rubiera, F. (2006). Outsourcing of advanced business services in the Spanish economy: explanation and estimation of the regional effects. Service Industries Journal, 26, 3, 267-285.

Mancebón Torrubia, M.J. \& Chavarría Lozano, P. (2001). La eficiencia productiva: empresa na- cional versus empresa extranjera. Información Comercial Española, 794, 23-53.

Martín-Roda, E.M. (1997). Madrid: ¿ciudad global o ciudad internacionalizada?: las IDE en la autonomía madrileña. Anales de Geografía de la Universidad Complutense de Madrid, 17, 209-221.

Méndez, R. (2001). Transformaciones económicas y reorganización territorial en la región metropolitana de Madrid. EURE, 27, 80, 141-161.

Méndez, R., García Palomares, J.C., Michelini, J.J., Sánchez Moral, S. \& Tébar, J. (2006). Metamorfosis de las grandes ciudades y nuevas estrategias de revitalización: el ejemplo de Madrid. Boletín de la Asociación de Geógrafos Españoles, 42, 7-30.

Méndez, R. (2007). Transformaciones económicas, entornos innovadores y reorganización de los territorios metropolitanos: algunas claves interpretativas. En A. Calatrava, S. Marcu, A. Melero \& R. Méndez (Eds.), Economías, mercados de trabajo y territorios metropolitanos en transformación (pp. 19-41). Madrid: Red ARETHUSE.

Merino de Lucas, F. \& Salas Fumás, V. (1996). Diferencias de eficiencia entre empresas nacionales y extranjeras en el sector manufacturero. Papeles de Economía Española, 66, 91-208.

Molina, M. \& Martín-Roda, E. (1998). La empresa multinacional en la Comunidad de Madrid. Serie Estudios Regionales BBVA. Madrid: BBVA.

Molina, M. (2002). Madrid, metrópolis global. Anales de Geografía de la Universidad Complutense, Vol. Extraordinario 2002, 1, 349-356.

Muñoz Guarasa, M. (2005). La internacionalización de los servicios en los países desarrollados. Comercio exterior, 55, 8, 692.

OCDE. (2007). OECD territorial reviews: Madrid, Spain. Paris: Autor.

Pascual Esteve, J.M. (1990). Los servicios avanzados a las empresas en la estrategia de las ciudades. Papeles de Economía Española, 42, 169-172.

Ramírez, B. (2006). Del funcionalismo industrial al de servicios: ¿la nueva utopía de la metrópoli postindustrial del valle de México? EURE, 32, 95, 61-74. 
Rodriguez-Pose, A. \& Zademach, H.M. (2003). Rising metropoli: the geography of mergers and acquisitions in Germany. Urban Studies, 40, 10, 1895-1923.

Rojas, E., Cuadrado-Roura, J.R. \& Fernández Güell, J.M. (2005). Gobernar las metrópolis. Washington DF: Banco Interamericano de Desarrollo.

Rubalcaba Bermejo, L. (2006). Ferias y congresos en una economía de servicios avanzados. Economistas, 24, 108, 350-354.

Sánchez Moral, S. (2006). Natalidad industrial y redes de empresas en España. Madrid: Ayuntamiento de Madrid.

Sassen, S. (1991). The global city. Princeton, NJ: Princeton University Press.

(1998). Ciudades en la economía global: enfoques teóricos y metodológicos. EURE, 24, 71, 5-25.

(2003). Localizando ciudades en circuitos globales. EURE, 29, 88, 5-27.
Soja, E.W. (2005). Algunas consideraciones sobre el concepto de ciudades- región globales. Ekonomiaz, 58, 45-75.

Taylor, P.J. (2001). Specifications of the world city network. Geographical Analysis, 33, 2, 181-194.

(2004). Porous Europe: european cities in global urban arenas. Tijdschrift voor Economische en Sociales Geografie, 95, 5, 527 538.

Taylor, P. J., Walker, D.R.F. \& Beaverstock, J.V. (2002). Firms and their global service networks. En S. Sassen (Ed.), Global networks, linked Cities (pp. 93-115). New York, London: Routledge.

Veltz, P. (1996). Mondialisation, villes et territoires. Paris: Presses Universitaires de France.

Wood, P.A., (2002). Knowledge-intensive services and urban innovativeness. Urban Studies, 39, 993-1002. 